\title{
Cold Plasma Jet Construction to Use in Medical, Biology and Polymer Applications
}

\author{
Khaled Lotfy ${ }^{1,2}$ \\ ${ }^{1}$ King Marriott Higher Institute of Engineering \& Technology, Alexandria, Egypt \\ ${ }^{2}$ University College of Taiyma, Tabuk University, Tabuk, KSA \\ Email: Khaledlotfy52@yahoo.com
}

How to cite this paper: Lotfy, K. (2017) Cold Plasma Jet Construction to Use in Medical, Biology and Polymer Applications. Journal of Modern Physics, 8, 1901-1910. https://doi.org/10.4236/jmp.2017.811113

Received: September 24, 2017

Accepted: October 28, 2017

Published: October 31, 2017

Copyright (c) 2017 by author and Scientific Research Publishing Inc. This work is licensed under the Creative Commons Attribution International License (CC BY 4.0).

http://creativecommons.org/licenses/by/4.0/

\section{(c) (i) Open Access}

\begin{abstract}
Cold atmospheric pressure plasma jets were capable of generating cold plasma plumes that were not confined by electrodes, which make them very enticing for biological, medical and polymer applications. During this work, experimental study of a low frequency, atmospheric plasma-jet discharge in nitrogen has been presented. The experimental operation of this device was conducted with commercially neon power supply. The discharge process operated by using nitrogen as input gas with different flow rates. The experimental results showed that the maximum plasma jet length of $7 \mathrm{~mm}$ was detected at $3 \mathrm{Kv}$ input voltage corresponding to $14 \mathrm{l} / \mathrm{min}$ as a nitrogen flow rate. The effect of distance from nozzle, nitrogen flow rate and input voltage on the plasma temperature was examined. The gas temperature decreased continuously as the flow rate of nitrogen increasing from $2 \mathrm{l} / \mathrm{min}$ to $14 \mathrm{l} / \mathrm{min}$ at $3 \mathrm{Kv}$ as a fixed input voltage.
\end{abstract}

\section{Keywords}

Cold Plasma, Neon Power Supply, Atmospheric Pressure, Plasma Jet

\section{Introduction}

These days, it's still quite uncommon for a normal person to come back and knowingly into contact with the plasma, the fourth state of matter. Our daily lives are dominated by the presence of the other three states (solid, liquid and gas), that we have a tendency to thus understand as a lot of acquainted. Despite the general belief, plasma is not rare, quite the opposite. More than $99 \%$ of the visible matter within the universe is among the plasma state [1]. The plasma is an ionized gas and includes of neutral, reactive and charged species. However, as will be simply found in nearly all textbooks and thesis on plasma technology, the term plasma was initially introduced in 1928 by the Noble 
winner Irving Langmuir throughout his analysis on the extension of the lifetime of tungsten filament light bulbs [2]. Not all ionized gas will be referred to as plasma. On the other hand, there's always a little degree of ionization in any gas. An ionized gas is defined as plasma once it's electrically neutral and contains a significant number of electrically charged particles, sufficient to have an effect on its electrical properties and behavior [3]. Plasma is often classified as either of thermal sort or non-thermal sort. In thermal plasma the ions and electrons are in thermodynamic equilibrium, wherever all particles have a similar temperature. Non-thermal plasmas have electrons that have abundant higher temperature than the ions and neutrals. Since the temperature of the gas is taken to be similar as the ion temperature. On the other hand, thermal and non-thermal plasmas also are named as equilibrium and non-equilibrium plasmas, respectively [4] [5].

Non-thermal plasmas utilized in medication and health care are in extremely non-equilibrium state and might be represented clearer by defining three temperature bands appropriate for various applications: A plasma with gas temperature of $100^{\circ} \mathrm{C}-150^{\circ} \mathrm{C}$ is beneficial for sterilization and decontamination of metallic medical devices, a plasma with a gas temperature of $60^{\circ} \mathrm{C}-100^{\circ} \mathrm{C}$ is often used for blood clotting and ablation of living tissues likewise as decontamination of a lot of temperature-sensitive plastic and glass medical devices, and a plasma with gas temperature of $20^{\circ} \mathrm{C}-60^{\circ} \mathrm{C}$ are often used for treatment of living tissue while not, or with least, damage to surrounding healthy tissue. Within the last twenty years non-equilibrium atmospheric plasma, additionally called cold atmospheric plasma, has undeniably risen an increasingly amount of interest each within the scientific and industrial worlds. Whereas its potential remains to be absolutely discovered, its role as one of the leading scientific innovations of the twenty-first century is less and less questioned. Over the last years, several plasma jet devices that produce a cold atmospheric-pressure plasma plume are investigated, as has their use with thermally sensitive materials and medical applications [6]-[14]. They will offer affordable reactivity with a low gas temperature at atmospheric pressure. They're easy to construct because what they are doing does not need any vacuum system and might be operated with numerous feeding gases under a wide vary of driving frequencies.

As a result of atmospheric pressure plasmas are operated in open air, the use of these plasmas could simply overcome the restrictions imposed by the presently offered vacuum-based plasma. Non-equilibrium atmospheric pressure plasmas have potential for medicine applications as a result of they are non-thermal and nontoxic, and since they have the potential to be realized in hand-held devices [15] [16]. Cold atmospheric plasma are used for medicine applications, like sterilization, [17] clotting, [18] wound healing [19] and even cancer treatment [20]. Additional considerably, atmospheric pressure plasmas will generate short-lived chemical species, which may be propelled toward the surface that's to be treated [8] and don't stay once the treatment is completed. 
An important feature of cold atmospheric plasma is its ability to produce a mixture of biologically active agents, such as Reactive Oxygen Species and Reactive Nitrogen Species, while remaining close to ambient temperature, which enables its safe application to sensitive materials like living cells and polymer. The plasma source for medicine applications should offer actually non-thermal plasma acting at atmospheric-pressure and close to the room temperature with none electrical and chemical risks. It should also be fascinating to utilize gases that are less costly, like air and nitrogen.

In this study, a nitrogen-plasma jet device has been designed, constructed and operated using a commercially neon power supply. This device was developed for treating thermally sensitive materials like cell biology and polymers. During this study the effect of input power supply and gas flow rate on the plasma jet has been investigated, to determine the optimum condition to use this device in medical, biological and polymer applications.

\section{Experimental Details}

The cold atmospheric plasma jet system is mainly composed of electrodes, dielectrics, voltage controller, nitrogen gas and a high-voltage power supply. The high-voltage power supply is a commercially available transformer for neon light (shown in Figure 1). This power supply is utilized in the cold atmospheric plasma to generate the plasma jet in order to cut the overall cost of the device by replacing the expensive RF power supply representing the major cost. The power supply has an output of $10 \mathrm{kV}, 30 \mathrm{~mA}$ and $20 \mathrm{kHz}$ which gives an output in the range of very low frequency of RF. This power supply has an overload, open circuit, earth leakage and short circuit protection. The input of this power supply is connected to $220 \mathrm{~V}, 12 \mathrm{~A}$ voltage controller. The voltage controller regulates the primary voltage of the high-voltage transformer. Figure 2 shows the electrode system of the plasma jet, this design consists of two parallel stainless steel disks separated by an insulator. The outer electrode (Cathode) and the inner electrode (anode) have the same thickness and diameter $15 \mathrm{~mm}$ and $2 \mathrm{~mm}$

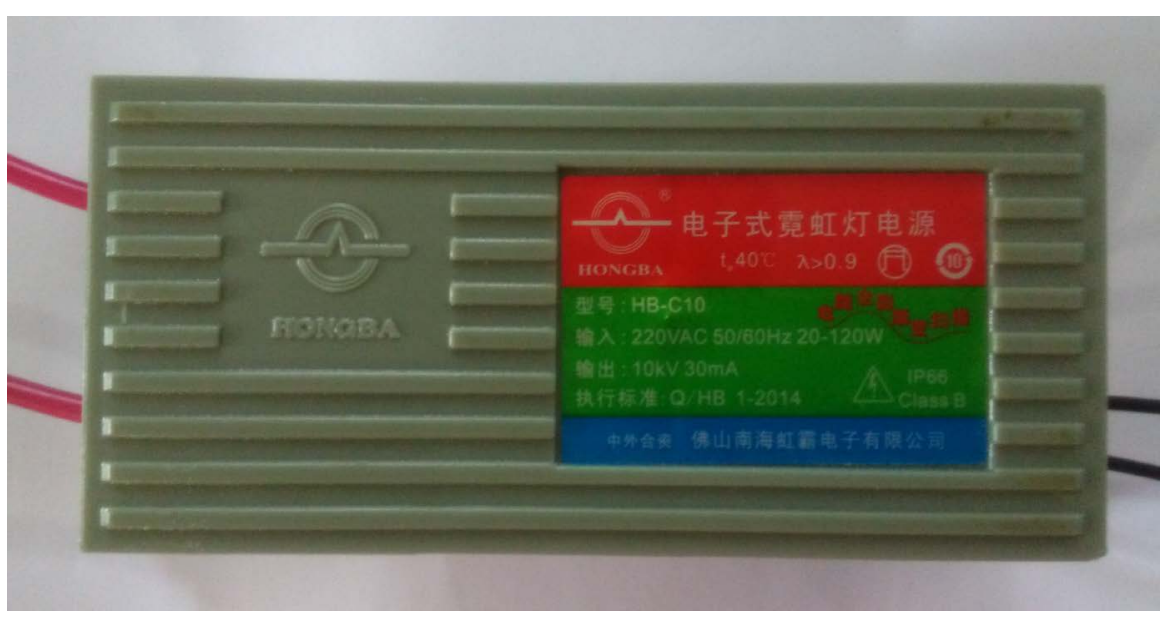

Figure 1. High-voltage power supply. 


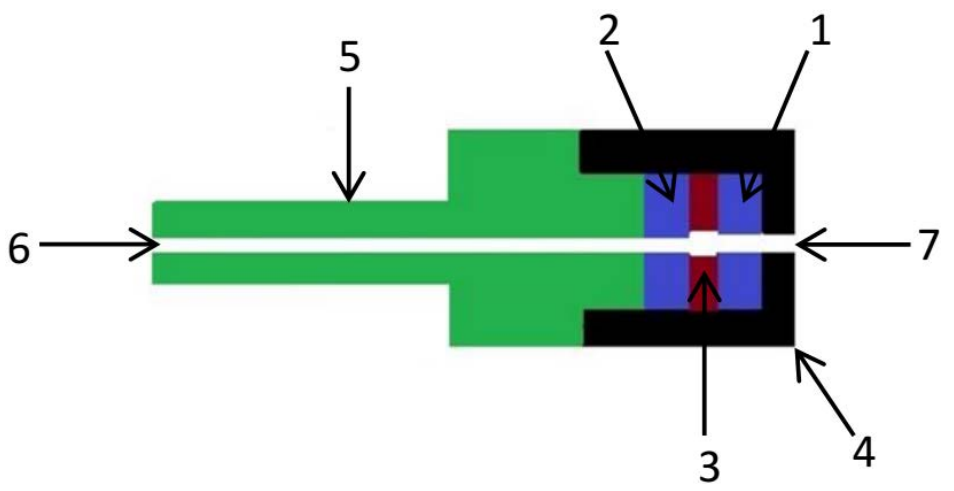

Figure 2. Electrode system of the plasma jet, 1 cathode, 2 anode, 3 Teflone insulator, 4 Teflon envelope, 5 cupper tube, 6 gas feeding and 7 plasma jet.

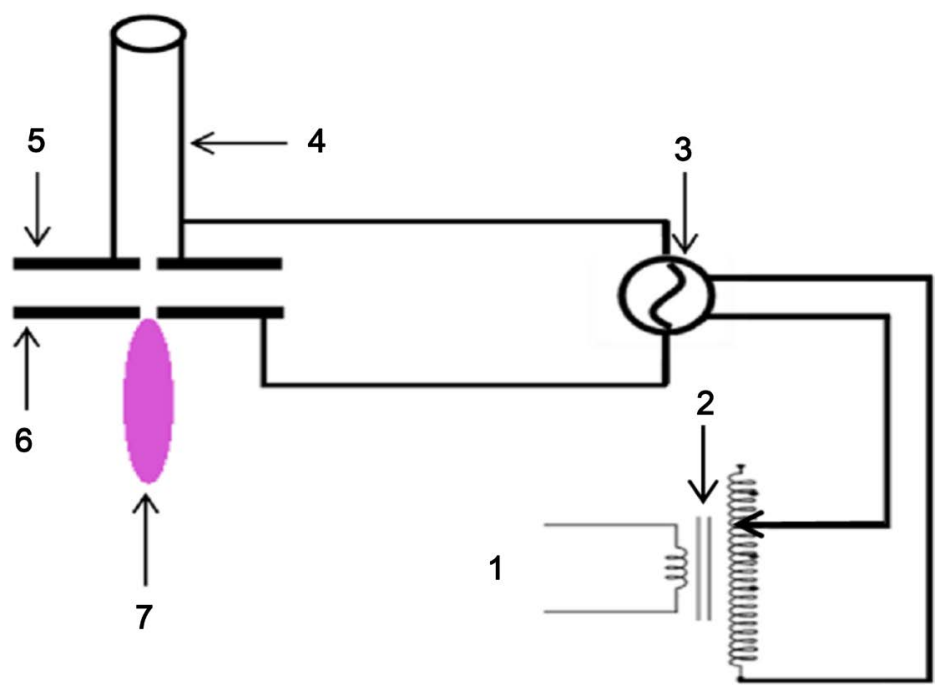

Figure 3. The electric circuit of cold atmospheric plasma jet device, 1 input electric source $220 \mathrm{~V}, 2$ voltage controllers, 3 neon power supply, 4 gas feeding through copper tube, 5 anode, 6 cathode and 7 plasma jet.

respectively. The two electrodes are separated by an insulator material, which made of Teflon. The Teflon disk has a $1 \mathrm{~mm}$ thickness and $15 \mathrm{~mm}$ in diameter. The two electrodes and Teflon disk have center hole of $1 \mathrm{~mm}$ and $1.2 \mathrm{~mm}$ diameter respectively, through center hole nitrogen gas is flowing. The output terminals of the power supply are connected to the cathode and anode terminals of the plasma jet via a $1 \mathrm{~mm}$ single copper isolated cable as can be seen in Figure 3. The gas flow system is responsible for delivering the gas to the plasma jet at the appropriate flow-rate. It consists of the gas storage cylinder, dual-stage gas flow regulator, and gas connection rubber hose. In this study Nitrogen gas was used to test the plasma jet operation. The nitrogen gas is stored in a high-pressure gas cylinder. The flow rate varies from $2 \mathrm{l} / \mathrm{min}$ to $16 \mathrm{l} / \mathrm{min}$. Due to excessive heating, continuous operation is not possible with flow rates below $21 / \mathrm{min}$.

\section{Result and Discussions}

Once nitrogen is introduced through the inner electrode and high-voltage ac 
power is applied, the plasma generation between the two electrodes. Sufficient voltage applied to nitrogen gas ionizes nitrogen atoms by driving off electrons. Free electrons can trigger further ionization of neighboring nitrogen species by a collision. This series of reactions convert the nitrogen gas to the plasma state, which is distinctly different from solid, liquid, and gas states. The device generates a room temperature plasma jet that passes through the hole of the inner electrode and extends up to $7 \mathrm{~mm}$ beyond the end of the Teflon evolve. The plasma jet can be touched without discomfort as can be seen in Figure 4. It can be touched by the bare hand or scanned over human skin without establishing a conductive pathway.

Figure 5 shows the Jet Phenomenology of plasma jet device operated with Nitrogen gas for different flow rates from 2 to $16 \mathrm{l} / \mathrm{min}$ at a fixed input voltage of 3 $\mathrm{kV}$. These images are captured using a digital camera. The length of the plasma jet in Figure 6 was measured visually. On the other hand, this figure shows the dependence of the length of the plasma jet with regard to different nitrogen flow rates at fixed input voltage. At $21 / \mathrm{min}$ of nitrogen flow rate, the plasma jet was only $1 \mathrm{~mm}$ long and its intensity was very weak. When the nitrogen flow rate was increased from 2 to $14 \mathrm{l} / \mathrm{min}$, the length of the plasma jet increased linearly to $7 \mathrm{~mm}$. At a flow rate in excess of $14 \mathrm{l} / \mathrm{min}$, the plasma jet length was saturated at approximately $7 \mathrm{~mm}$.

However, the plasma temperature is one the most necessary parameters in biomedical applications attributable to the sensitivity of living cells and their

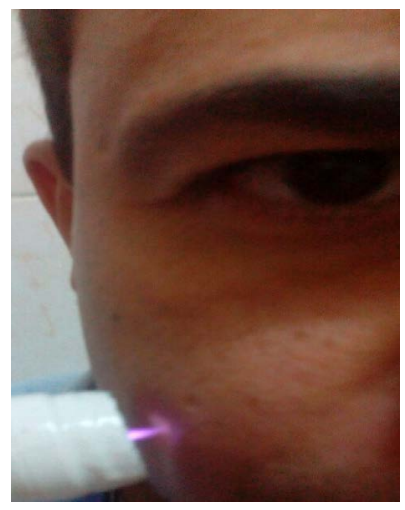

Figure 4. Human face contacting with the nitrogen-plasma jet without any electrical shock.

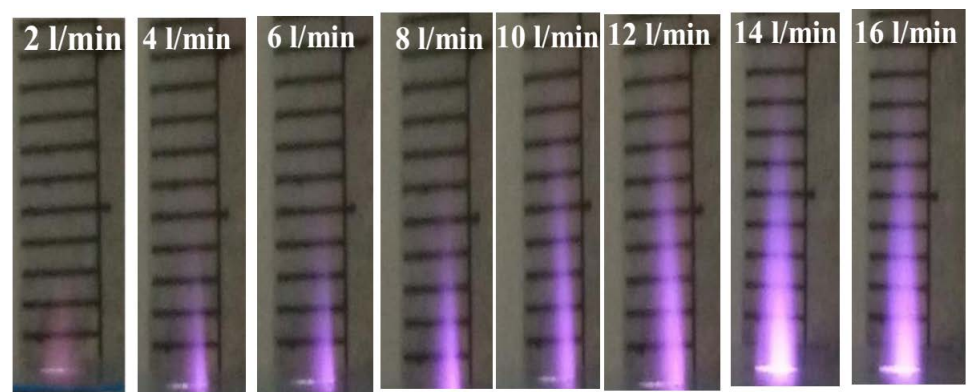

Figure 5. The Jet Phenomenology of nitrogen plasma jet. 


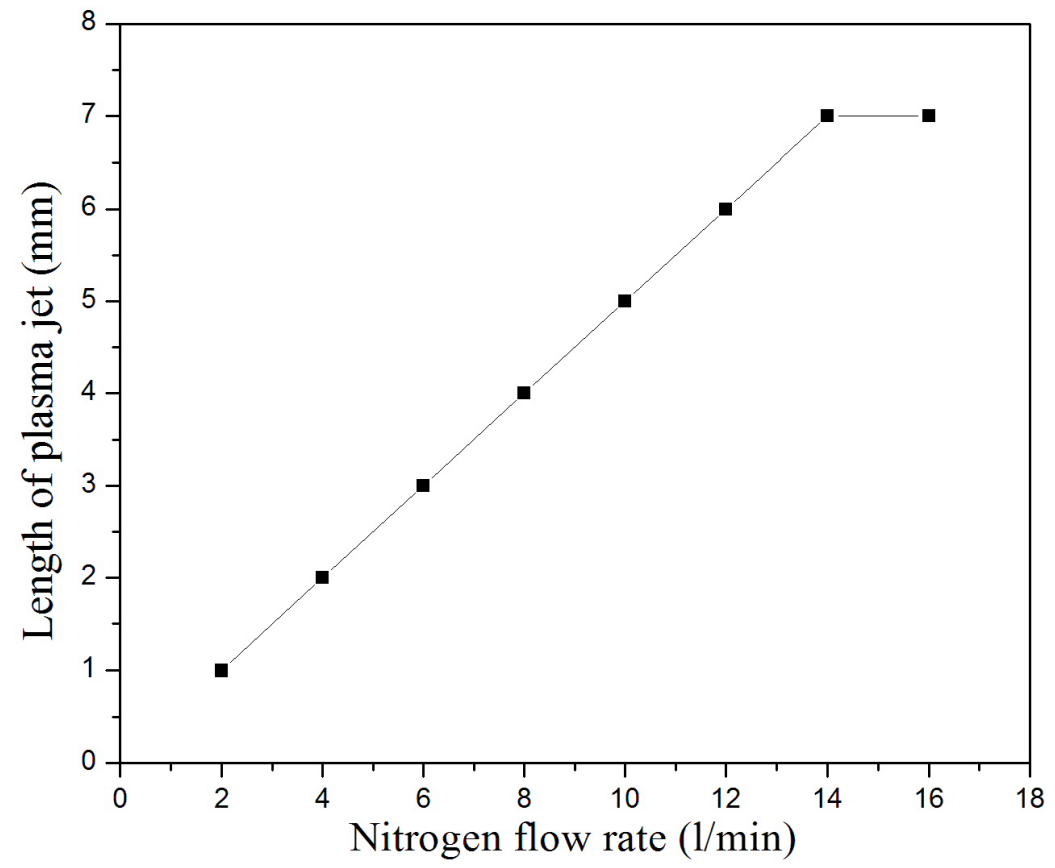

Figure 6. The nitrogen flow rate effect on plasma jet length at $3 \mathrm{Kv}$ as a fixed input voltage.

inner organs like proteins. The plasma temperature should stay below an exact quantity of degree. During this method, plasma won't have any thermal effects like ablation or clotting. To determine the plasma temperature, a thermocouple was used to observe the plasma temperature behavior. In this experiment, the effect of three variables on plasma temperature was examined; a distance from nozzle, a different nitrogen flow rate and a different input voltage.

Figure 7 shows the gas temperatures of the plasma jets at the different distance from the cathode at constant flow rate and input voltage $14 \mathrm{l} / \mathrm{min}$ and $3 \mathrm{Kv}$ respectively. The axial position $\mathrm{x}$ in Figure 7 represents the distance from the outer electrode. From this figure, it can be seen that the gas temperature increase continuously by decrease the axial position. Also, the gas temperature increases continuously for the same position by increasing the operation time. In the case of $\mathrm{x}=7 \mathrm{~mm}$ the plasma jet approaches room temperature $\left(27^{\circ} \mathrm{C}\right)$, Even the operation time reach $35 \mathrm{~min}$, the gas temperature is as low as $46^{\circ} \mathrm{C}$. Besides, the different plasma temperature between the operation time at $0 \mathrm{~min}$ and $35 \mathrm{~min}$ increase by decreasing the axial position.

However, the gas temperature of cold plasmas is taken to be approximately the same as the ion temperature. This is true even though the electrons can have temperatures of several tens of thousands degrees. Since the mass of the electrons is much lower than the mass of the heavier gas components of ions and neutrals, the electrons do not transfer much of their thermal energy as heat to the gas component or the environment [21].

The gas temperatures of the plasma jets at different air flow rates, corresponding to the input voltage ( $3 \mathrm{Kv}$ ) and distance from the cathode equal $7 \mathrm{~mm}$ 


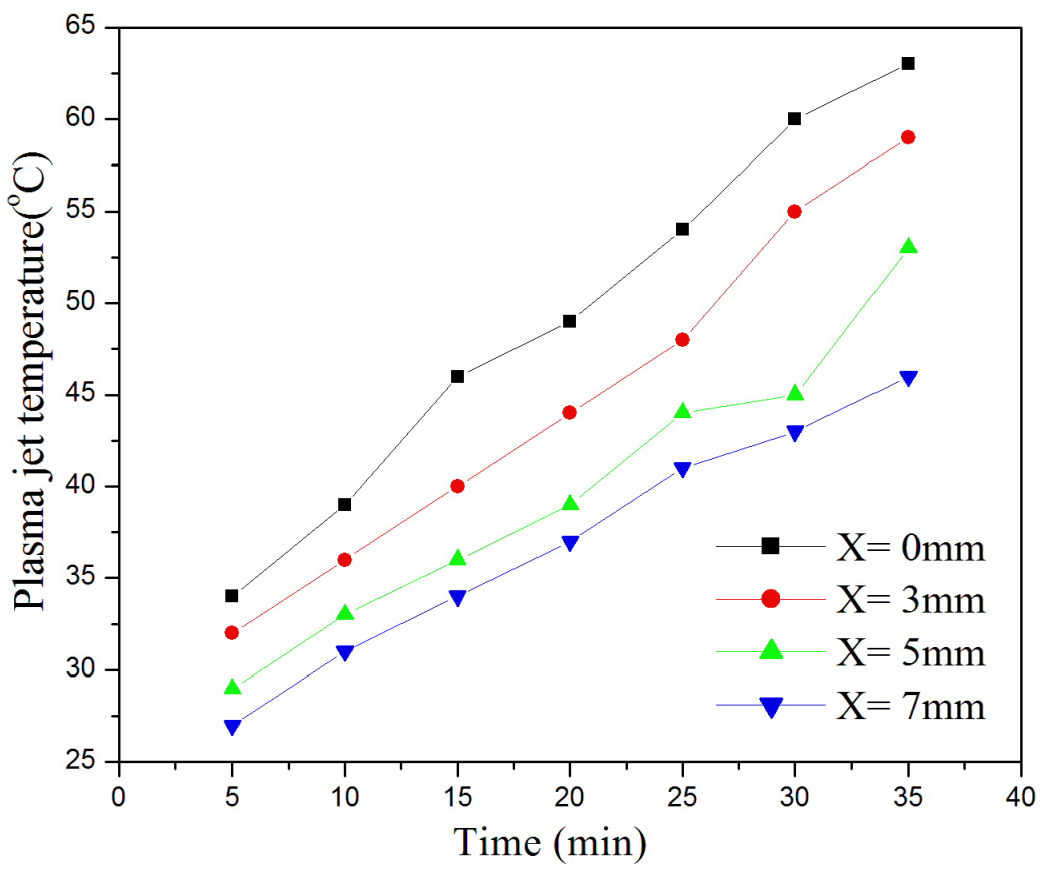

Figure 7. The plasma jet temperature at the different distance from cathode corresponding $14 \mathrm{l} / \mathrm{min}$ and $3 \mathrm{Kv}$ as nitrogen flow rate and input voltage respectively.

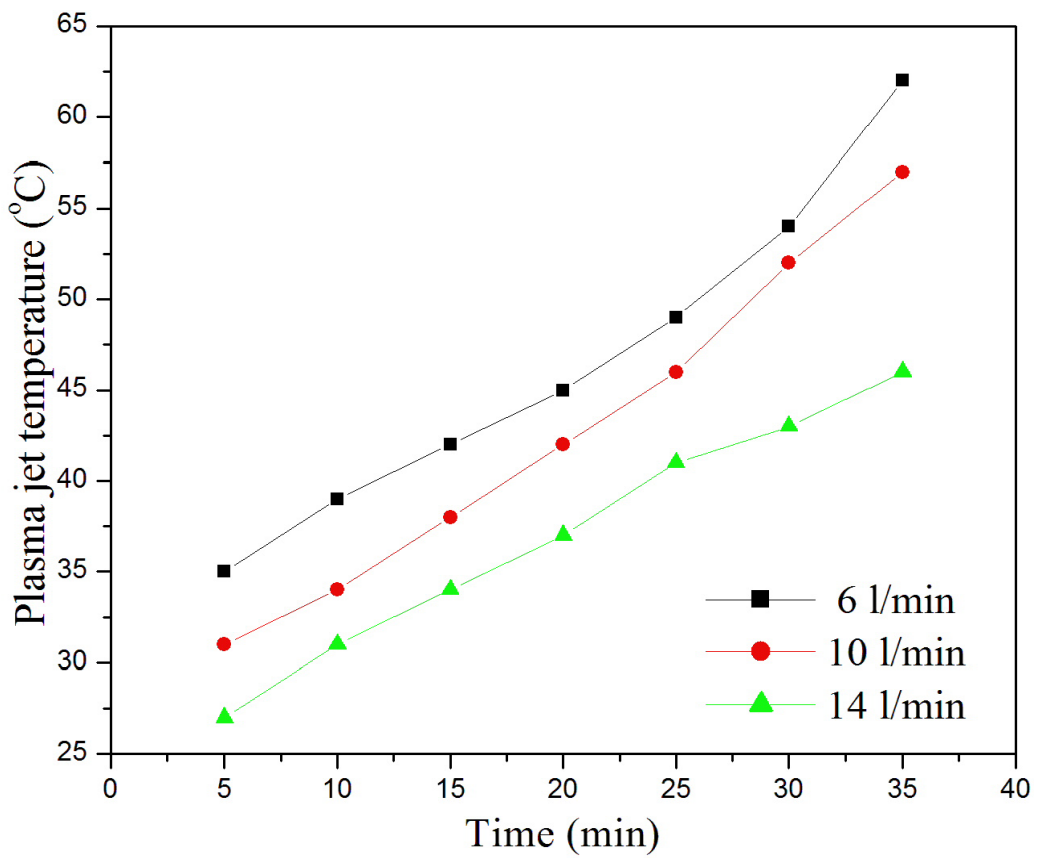

Figure 8. The plasma jet temperature at different nitrogen flow rats, corresponding to the input voltage $(3 \mathrm{Kv})$ and distance from the cathode $7 \mathrm{~mm}$.

can be seen in Figure 8. This figure clears that, the gas temperature decreases continuously as the flow rate of nitrogen increasing from $6 \mathrm{l} / \mathrm{min}$ to $14 \mathrm{l} / \mathrm{min}$. When plasma operated at $14 \mathrm{l} / \mathrm{min}$ the nitrogen gas is ejected through the outer electrode at a higher speed producing a high-pressure afterglow and then cooling near room temperature. As can be seen from the figure, the gas temperature 


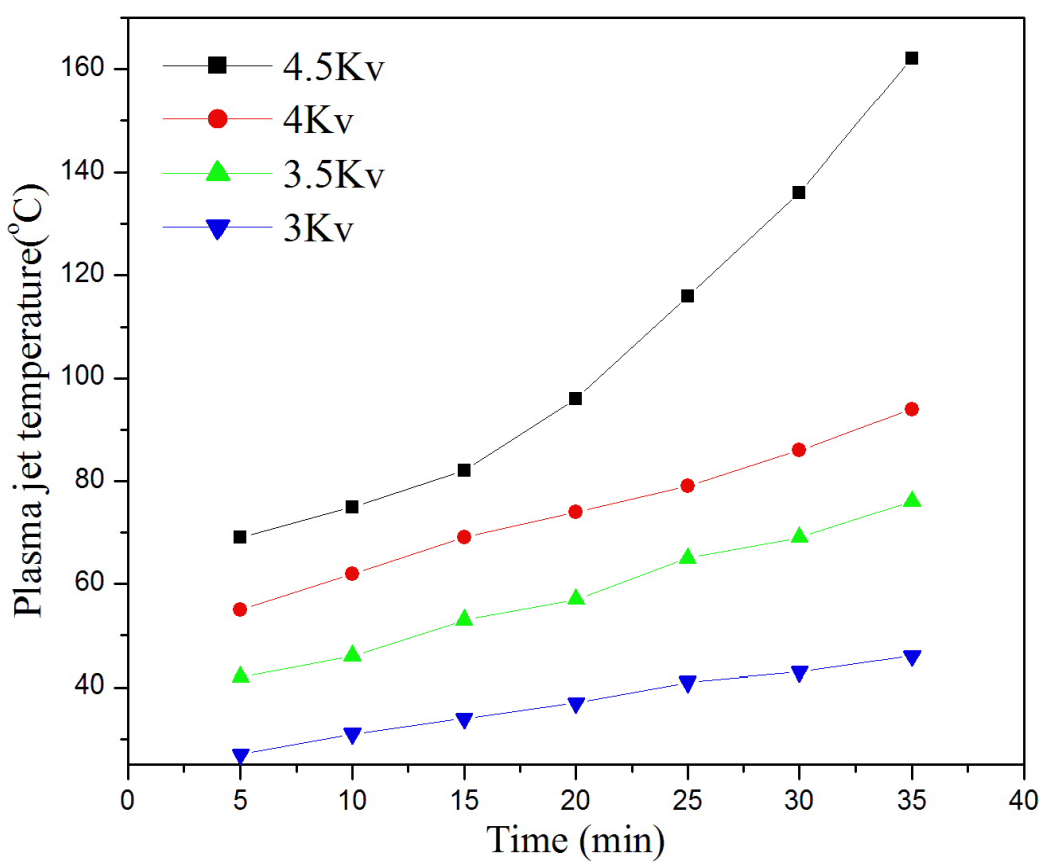

Figure 9. The plasma jet temperature at different input voltage corresponding to $14 \mathrm{l} / \mathrm{min}$ and $7 \mathrm{~mm}$ as a nitrogen flow rate and distance from cathode respectively.

of plasma increased with increasing of the operation time. The temperature increased by $19^{\circ} \mathrm{C}$ to $27^{\circ} \mathrm{C}$ during $35 \mathrm{~min}$ operational time for nitrogen gas.

The increasing effect of the input voltage at $141 / \mathrm{min}$ as a fixed flow rate is displayed in Figure 9. As it can be seen in this figure, corresponding a $7 \mathrm{~mm}$ as a fixed distance from cathode electrode, increasing the given voltage to the carrier gas will cause an increase in ionizing rate which will lead to a higher gas temperature as well. The temperature increased by $19^{\circ} \mathrm{C}$ to $93^{\circ} \mathrm{C}$ during $35 \mathrm{~min}$ operational time for plasma jet. In the case of $3 \mathrm{Kv}$ the temperature increased from $27^{\circ} \mathrm{C}$ to $46^{\circ} \mathrm{C}$ during $35 \mathrm{~min}$, these conditions may be suitable for treatment of living tissue. On the other hand, In the case of $4 \mathrm{Kv}$, the temperature increased from $55^{\circ} \mathrm{C}$ to $94^{\circ} \mathrm{C}$ during $35 \mathrm{~min}$, these conditions can be used for blood coagulation and ablation of living tissues as well as decontamination of more temperature-sensitive plastic and glass medical devices. Besides, the temperature increased from $69^{\circ} \mathrm{C}$ to $162^{\circ} \mathrm{C}$ during $35 \mathrm{~min}$ when input voltage adjusted at 4.5 $\mathrm{Kv}$, these conditions are useful for sterilization and decontamination of metallic medical devices. The result proved that, this device is a type of cold plasma jet. Also, this temperature is appropriate for polymer and biomedical applications [22]. This design will be useful to initiate research in several fields such as low temperature plasma, polymer and biomedical applications.

\section{Conclusions}

The Low-cost cold atmospheric plasma jet device has been designed, constructed and operated in our laboratory. The jet phenomenology was investigated to detect the jet length for carrier gas at different flow rates. The effect of distance 
from nozzle, nitrogen flow rate and the input voltage on plasma temperature was examined. The operation of the device has been sustained by a stable glow discharge mode without transition to arc. The result improved that, the plasma temperature is independent on the distance from nozzle, nitrogen flow rate and the input voltage. The control of plasma temperature in this device makes it is easy to use in many fields. This device is suitable for treatment of living tissue, blood coagulation, and ablation of living tissues, sterilization and decontamination of metallic medical devices. The advantages of this device can be surmised in the following,

- The potential cost reduction of apparatuses.

- Operated in very low-frequency RF.

- Don't need to a cooling system.

- Don't need to any vacuum system.

- Might be operated with numerous feeding gases.

- The device can be constructed in a small area of the laboratory.

- The device can be used in many applications.

- Easier handling and maintenance.

- There is no limitation in the size of the treated objects.

In future we will use this device in many applications like polymer functionalization, kill bacteria, wound healing, tooth bleaching and cell cancer treatment.

\section{References}

[1] Tendero, C., Tixier, C., Tristant, P., Desmaison, J. and Leprince, P. (2006) Atmospheric Pressure Plasmas: A Review. Spectrochimica Acta Part B: Atomic Spectroscopy, 61, 2. https://doi.org/10.1016/j.sab.2005.10.003

[2] Tonks, L. (1967) The Birth of Plasma. American Journal of Physics, 35, 857. https://doi.org/10.1119/1.1974266

[3] Fridman, A. and Friedman, G. (2012) Plasma Medicine. John Wiley \& Sons, Hoboken. https://doi.org/10.1002/9781118437704

[4] Raizer, Y.P. (1991) Gas Discharge Ephysics. Springer-Verlag, Berlin. https://doi.org/10.1007/978-3-642-61247-3

[5] Fridman, A. (2008) Plasmachemistry. Cambridge University Press, Cambridge.

[6] Kolb, J.F., Mohamed, A.-A.H., Price, R.O., Swanson, R.J., Bowman, A., Chiavarini, R.L., Stacey, M. and Schonenbach, K.H. (2008) Cold Atmospheric Pressure Air Plasma Jet for Medical Applications. Applied Physics Letters, 92, 1-3. https://doi.org/10.1063/1.2940325

[7] Lu, X.-P., Jiang, Z.-H., Xiong, Q., Tang, Z.,-Y., Hu, X.-W. and Pan, Y. (2008) An 11 $\mathrm{cm}$ Long Atmospheric Pressure Cold Plasma Plume for Applications of Plasma Medicine. Applied Physics Letters, 92, Article ID: 081502. https://doi.org/10.1063/1.2883945

[8] Hong, Y.C. and Uhm, H.S. (2006) Microplasmajetat Atmospheric Pressure. Applied Physics Letters, 89, Article ID: 221504. https://doi.org/10.1063/1.2400078

[9] Zhang, X., Li, M., Zhou, R., Feng, K. and Yang, S. (2008) Ablation of Liver Cancer Cells In Vitro by a Plasma Needle. Applied Physics Letters, 93, Article ID: 021502. https://doi.org/10.1063/1.2959735 
[10] Hong, Y.C., Uhm, H.S. and Yi, W.J. (2008) Atmospheric Pressure Nitrogen Plasma Jet: Observation of Striated Multilayer Discharge Patterns. Applied Physics Letters, 93, Article ID: 051504. https://doi.org/10.1063/1.2969287

[11] Nie, Q.-Y., Ren, C.-S., Wang, D.-Z. and Zhang, J.-L. (2008) A Simple Cold Ar Plasma Jet Generated with a Floating Electrode at Atmospheric Pressure. Applied Physics Letters, 93, Article ID: 011503. https://doi.org/10.1063/1.2956411

[12] Deng, X.T., Shi, J.J. and Kong, M.G.J. (2007) Protein Destruction by a Helium Atmospheric Pressure Glow Discharge: Capability and Mechanisms. Applied Physics, 101, Article ID: 074701. https://doi.org/10.1063/1.2717576

[13] Hong, Y.C., Cho, S.C., Kim, J.H. and Uhm, H.S. (2007) A Long Plasma Column in a Flexible Tube at Atmospheric Pressure. Physics of Plasmas, 14, Article ID: 074502. https://doi.org/10.1063/1.2750652

[14] Hong, Y.C., Cho, S.C. and Uhm, H.S. (2007) Twin Injection-Needle Plasmas at Atmospheric Pressure. Applied Physics Letters, 90, Article ID: 141501. https://doi.org/10.1063/1.2718483

[15] Iza, F., Lee, J.K. and Kong, M.G. (2007) Electron Kinetics in Radio-Frequency Atmospheric Pressure Microplasmas. Physical Review Letters, 99, Article ID: 075004. https://doi.org/10.1103/PhysRevLett.99.075004

[16] Iza, F., Kim, G.J., Lee, S.M., Lee, J.K., Walsh, J.L., Zhang, Y.T. and Kong, M.G. (2008) Microplasmas: Sources, Particle Kinetics, and Biomedical Applications. Plasma Processes and Polymers, 5, 322. https://doi.org/10.1002/ppap.200700162

[17] Laroussi, M. (2005) Low Temperature Plasma Based Sterilization: Overview and State of-the-Art. Plasma Processes and Polymers, 2, 391. https://doi.org/10.1002/ppap.200400078

[18] Kalghatgi, S.U., Fridman, G., Cooper, M., Nagaraj, G., Peddinghaus, M., Balasubramanian, M., Vasilets, V.N., Gutsol, A.F., Fridman, A. and Friedman, G. (2007) Mechanism of Blood Coagulation by Nonthermal Atmospheric Pressure Dielectric Barrier Discharge Plasma. IEEE Transactions on Plasma Science, 35, 1559. https://doi.org/10.1109/TPS.2007.905953

[19] Fridman, G., Friedman, G., Gutsol, A., Shekhter, A.B., Vasilets, V.N. and Fridman, A. (2008) Applied Plasma Medicine. Plasma Processes and Polymers, 5, 503. https://doi.org/10.1002/ppap.200700154

[20] Kim, G.C., Kim, G.J., Park, S.R., Jeon, S.M., Seo, H.J., Iza, F. and Lee, J.K. (2009) Air Plasma Coupled with Antibody-Conjugated Nanoparticles: A New Weapon against Cancer. Journal of Physics D: Applied Physics, 42, Article ID: 03200. https://doi.org/10.1088/0022-3727/42/3/032005

[21] Wiesemann, K. (2014) A Short Introduction to Plasma Physics.

[22] Laroussi, M. (2009) Low-Temperature Plasmas for Medicine? IEEE Transactions on Plasma Science, 37, 6. https://doi.org/10.1109/TPS.2009.2017267 